\title{
A MATEMÁTICA ESTÁ EM TUDO: REVISTA DE ATIVIDADES PARA AUXÍLIO NO APRENDIZADO DE MATEMÁTICA DO ENSINO MÉDIO
}

DOI: 10.37702/2175-957X.COBENGE.2021.3540

Susie Cristine Keller - susie.keller@ufsc.br

UFSC

Rua Orestes Guimarães 480

89204-060 - Joinville - SC

Valquiria Rafaela Radunz - valrradunz@gmail.com Universidade Federal de Santa Catarina

Rua João Vogelsanger 346

89218-080 - Joinville - SC

Tatiana Renata Garcia - tatiana.rgarcia@gmail.com

UFSC

João Colin 2700

89218-035 - Joinville - SC

Resumo: Esta revista foi desenvolvida com o intuito de contribuir com o ensino da matemática para os alunos do terceiro ano do ensino médio, e os estudantes das fases iniciais dos cursos do Centro Tecnológico de Joinville (CTJ) da Universidade Federal de Santa Catarina (UFSC). O objetivo desta revista é retomar alguns conteúdos da disciplina de matemática de forma lúdica e descomplicada, a fim de desenvolver o interesse dos leitores e aprimorar a sua compreensão sobre os assuntos abordados.

Palavras-chave: ensino, matemática, ensino médio 


\section{A MATEMÁTICA ESTÁ EM TUDO: REVISTA DE ATIVIDADES PARA AUXÍLIO NO APRENDIZADO DE MATEMÁTICA DO ENSINO MÉDIO}

\section{INTRODUÇÃO}

O Centro Tecnológico de Joinville, do campus da UFSC Joinville, possui um espaço destinado a atividades de extensão com escolas de Joinville e região, este é chamado de Espaço de Ciência e Tecnologia (ECT), cujo objetivo é conectar a sociedade à universidade e promover a democratização da ciência. O espaço oferece oficinas sobre meio ambiente, robótica e matemática, entre outros, além de possuir jogos educativos e objetos interativos relacionados aos assuntos abordados. Diversos jogos já foram desenvolvidos pela equipe, inclusive sobre o tema da matemática onde o enfoque foram as matrizes (KELLER et al., 2017).

Antes da pandemia, o ECT era aberto para visitas, e frequentemente recebia turmas de escolas públicas e particulares, com o intuito tanto de popularizar a ciência e a tecnologia, como também divulgar o Campus e os cursos ofertados (Engenharia Aeroespacial, Engenharia Automotiva, Engenharia Ferroviária e Metroviária, Engenharia Civil de Infraestrutura, Engenharia Mecatrônica, Engenharia Naval, Engenharia de Transportes e Logística e Bacharelado em Ciência e Tecnologia). Durante o período de interação com os visitantes, a maior parte deles demonstrava interesse pelos conteúdos abordados, mas quando questionados se gostariam de se matricular nos cursos de ciências exatas disponibilizados no CTJ, alguns afirmavam que seria difícil, principalmente porque a base das matérias é a matemática.

Percebe-se, com isso, que a matemática ainda é vista como algo complicado e desinteressante, que se aprende apenas para "passar de ano", quando, na verdade, está presente em todas as áreas do cotidiano e poderia ser ensinada de maneira descontraída e instigante. De acordo com Groenwald e Timm (2002 apud CABRAL, 2006) a utilização de jogos como palavras cruzadas no aprendizado da matemática, fornecem não só o caráter lúdico ao ensino, como também estimulam os alunos no desenvolvimento de técnicas intelectuais.

Dessa forma, a revista A Matemática está em Tudo - Ensino Médio foi pensada como uma maneira de mostrar a matemática de forma divertida, para instigar o interesse sobre o assunto, e auxiliar no seu estudo. Além dos alunos do ensino médio, a revista foi elaborada para também contribuir com o aprendizado de acadêmicos do CTJ, pois, através do conhecimento empírico e dados oficiais da UFSC, sabe-se que existe uma parcela de estudantes com dificuldades nas matérias de matemática das fases iniciais dos cursos.

\section{SOBRE A REVISTA}

A Matemática está em tudo é uma revista desenvolvida pelo Espaço de Ciência e Tecnologia, composta por informativos sobre o Centro Tecnológico de Joinville e atividades cujo conteúdo é relativo às disciplinas de matemática oferecidas no ensino médio.

\subsection{Objetivo}

Segundo relatório executivo da Andifes divulgado pela UFSC, e noticiado por Torres e Trevisol (2019), cerca de 15\% dos alunos que ingressam nos cursos do CTJ demonstram dificuldades de aprendizagem. Esse problema pode estar relacionado ao histórico do ensino vivenciado ao longo do tempo, dados de uma pesquisa realizada em São Paulo 
apontam que o processo de ensino-aprendizagem das escolas públicas pode afetar o desempenho dos alunos no ensino médio. (NETO et al., 2015).

Desde o ensino fundamental a matemática é vista como algo maçante, e é associada a decorar fórmulas, e, enquanto a sociedade depende cada vez mais da matemática, seu ensino não acompanha esse desenvolvimento. A pesquisa de Aimi et al. (2004 apud SANTOS, 2005, p. 27) que questionou os motivos pelos quais os alunos não gostam de matemática, confirmou que $75 \%$ da amostra utilizada não gosta de matemática por ser complicada e difícil.

Ademais, os bolsistas do ECT que recebem visitas de alunos do ensino médio, percebem certa dificuldade ao desenvolver atividades matemáticas com eles. Muitos deles demonstram possuir pouco, ou nenhum, conhecimento sobre os assuntos vistos em classe. Mesmo quando as dinâmicas propostas envolvem o conteúdo da grade curricular atual das turmas visitantes, a maioria dos alunos não possui a base necessária para compreender o material apresentado.

Em vista disso, a revista foi proposta como um passatempo educativo para auxiliar no estudo da matemática para alunos do terceiro ano do ensino médio e calouros da universidade. O principal propósito é oferecer os assuntos de maneira simplificada e dinâmica, para facilitar a aprendizagem dos leitores e aumentar seu engajamento.

\section{$2.2 \quad$ Método}

A proposta de auxílio no aprendizado foi baseada nos resultados obtidos durante as visitas ao ECT, onde diversos alunos de ensino médio e fundamental foram estimulados a compreender melhor a matemática através de jogos e atividades. Ao observar o comportamento resultante, percebeu-se o aumento de interesse de forma generalizada sobre o assunto.

Além disso, foram verificados estudos sobre a aplicação de atividades lúdicas em sala de aula, e as informações, adaptadas para a aplicação na revista A Matemática está em tudo. Sabe-se que "O uso de jogos e curiosidades no ensino da Matemática tem o objetivo de fazer com que os alunos gostem de aprender essa disciplina, mudando a rotina da classe e despertando o interesse do aluno envolvido." (SILVA et al., 2013, p. 6).

CABRAL (2006) compartilha deste ponto de vista e alega que as atividades lúdicas não só estimulam o aprendizado, como também contribuem para o desenvolvimento em outras áreas:

[...] Além disso, as atividades lúdicas podem ser consideradas como uma estratégia que estimula o raciocínio levando o aluno a enfrentar situações conflitantes relacionadas com seu cotidiano e, também, a utilização dos jogos vem confirmar o valor formativo da matemática, não no sentido apenas de auxiliar na estruturação do pensamento e do raciocínio dedutivo, mas, também, de auxiliar na aquisição de atitudes. (CABRAL, 2006, p.19).

Por conseguinte, o método escolhido para a atingir o objetivo da revista é divertido e simples, mas capaz de desafiar os leitores.

\subsection{Atividades}

Visto que as atividades lúdicas contribuem para o aprendizado da matemática, fazse necessária a decisão sobre qual tipo de passatempo melhor se encaixa no objetivo. Com isso esclarecido, foram definidos exercícios de vários formatos relacionados à matéria. 


\section{Atividade 01 - Qual é a palavra?}

$\mathrm{Na}$ atividade "Qual é a palavra?", o leitor é desafiado a resolver equações para descobrir as letras, e completar as palavras. Utilizando os conhecimentos sobre logaritmo, radiciação, trigonometria, entre outros, o leitor encontrará o nome de cada curso oferecido no CTJ. O estímulo é para que a pessoa consiga resolver, busque pesquisar sobre o assunto e se instigue a conseguir sozinha, contudo, as resoluções estarão disponíveis no site e nas redes sociais do Espaço de Ciência e Tecnologia. A Figura 1 mostra a atividade em questão.

Figura 1 - Atividade 01.

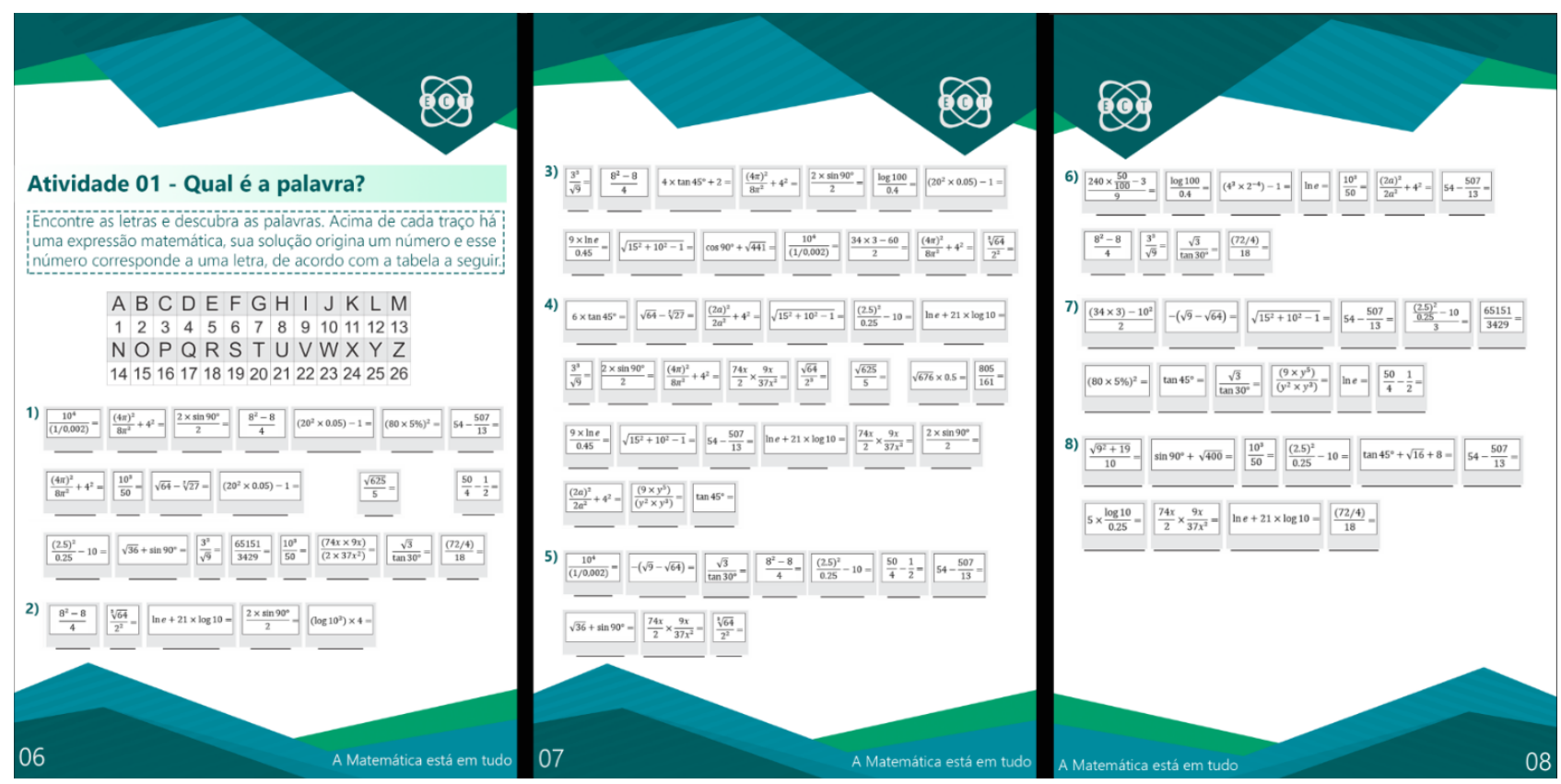

Fonte: Adaptado de A Matemática está em tudo (2020).

O intuito dessa atividade é permitir que o leitor exercite os conhecimentos matemáticos trabalhados durante o ensino médio, e consiga desenvolver seus próprios métodos de resolução de cálculos. Essa metodologia refere-se ao conhecimento sobre simplificações, que não só simplificam alguns cálculos, como também reduzem o tempo para a sua resolução. $O$ arquivo de resoluções para essa atividade é composto por várias dicas para facilitar o desenvolvimento dos cálculos.

As respostas são separadas por ordem de resultado, ou seja, os problemas que resultam em 1 e correspondem a letra A são os primeiros na resolução disponibilizada no site do ECT, e um exemplo do arquivo pode ser visto na Figura 2.

\section{Atividade 02 - Caça-Palavras}

O caça-palavras é uma atividade comumente encontrada em jornais e revistas, e esse foi elaborado com a temática do Centro Tecnológico de Joinville. Arranjadas de modo que possam ser lidas da esquerda para a direita, e de cima para baixo, as palavras que devem ser encontradas fazem referência aos cursos oferecidos no campus, e estão destacadas do texto auxiliar que precede a atividade. A estrutura elaborada pode ser vista na Figura 3. 
Figura 2 - Resolução de um dos problemas da Atividade 01.

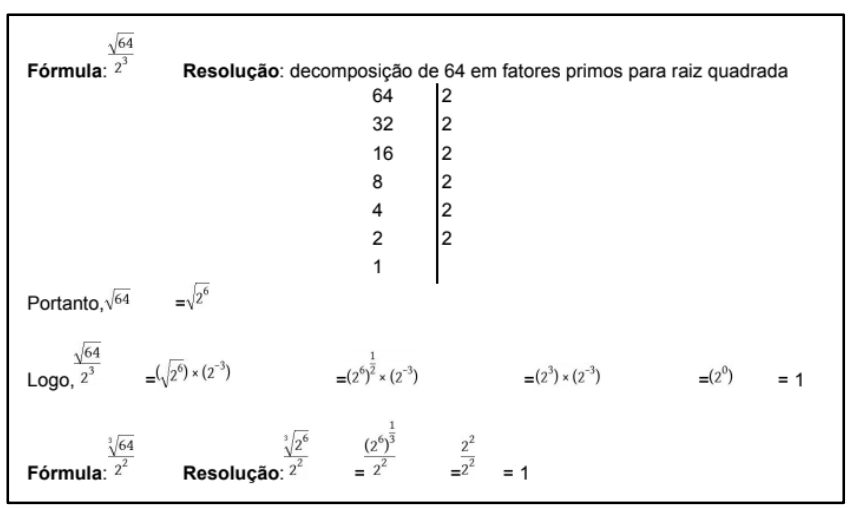

Fonte: Adaptado de A Matemática está em tudo (2020).

\section{Atividade 03 - Desafios de Lógica}

$\mathrm{Na}$ Figura 3 também se observa um conjunto de perguntas chamado "Desafios de Lógica", que compõem a terceira atividade. Esse tipo de atividade é conhecido por se adequar a todos as idades pois pode possuir diferentes níveis de dificuldade, além de ser um excelente passatempo para aqueles que querem se divertir, aprimorar a lógica e exercitar a concentração.

Os problemas exigem que o leitor desenvolva o raciocínio, o pensamento crítico e consiga completar isso com a matemática.

Figura 3 - Atividades 02 e 03

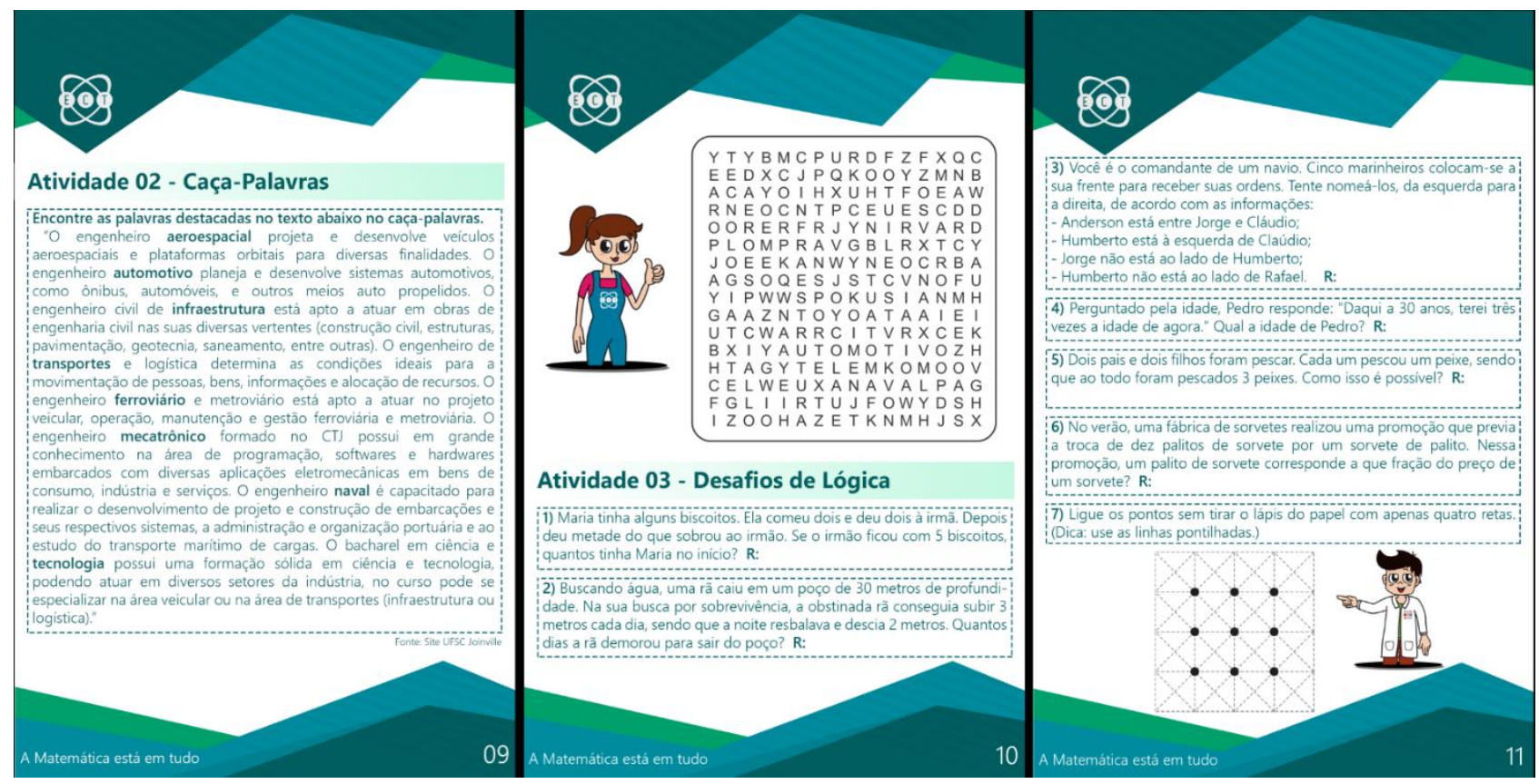

Fonte: Adaptado de A Matemática está em tudo (2020). 


\section{Atividade 04 - Palavras Cruzadas}

As palavras cruzadas de termos matemáticos formam a próxima atividade, e são dispostas no sentido vertical e horizontal. Comumente encontrada em jornais e revistas, o jogo de palavras cruzadas desenvolvido em "A Matemática está em tudo" instiga o leitor a testar o conhecimento matemático de maneira mais teórica, se comparado às outras atividades. Na Figura 4 observa-se que assuntos comuns da grade curricular fazem parte do exercício, bem como definições incomuns para instigar a curiosidade do leitor.

\section{Atividade 05 - Sudoku}

Na sequência, um minijogo de Sudoku é apresentado em formato inusitado. No jogo padrão o objetivo é preencher as células vazias com um número em cada célula, de maneira que cada coluna, linha e região contenha os números de 1 a 9 apenas uma vez. Para a resolução dessa atividade, o leitor deve resolver algumas equações a fim de saber qual número as letras representam, para então seguir com as regras de um Sudoku comum. As equações propostas nesse exercício são reutilizadas da Atividade 01, e, portanto, as resoluções encontram-se no arquivo de respostas comentado anteriormente. Na Figura 4 pode-se verificar a estrutura do jogo proposto, bem como as equações cujas respostas representam as letras que preenchem a grade.

Figura 4 - Atividades 04 e 05

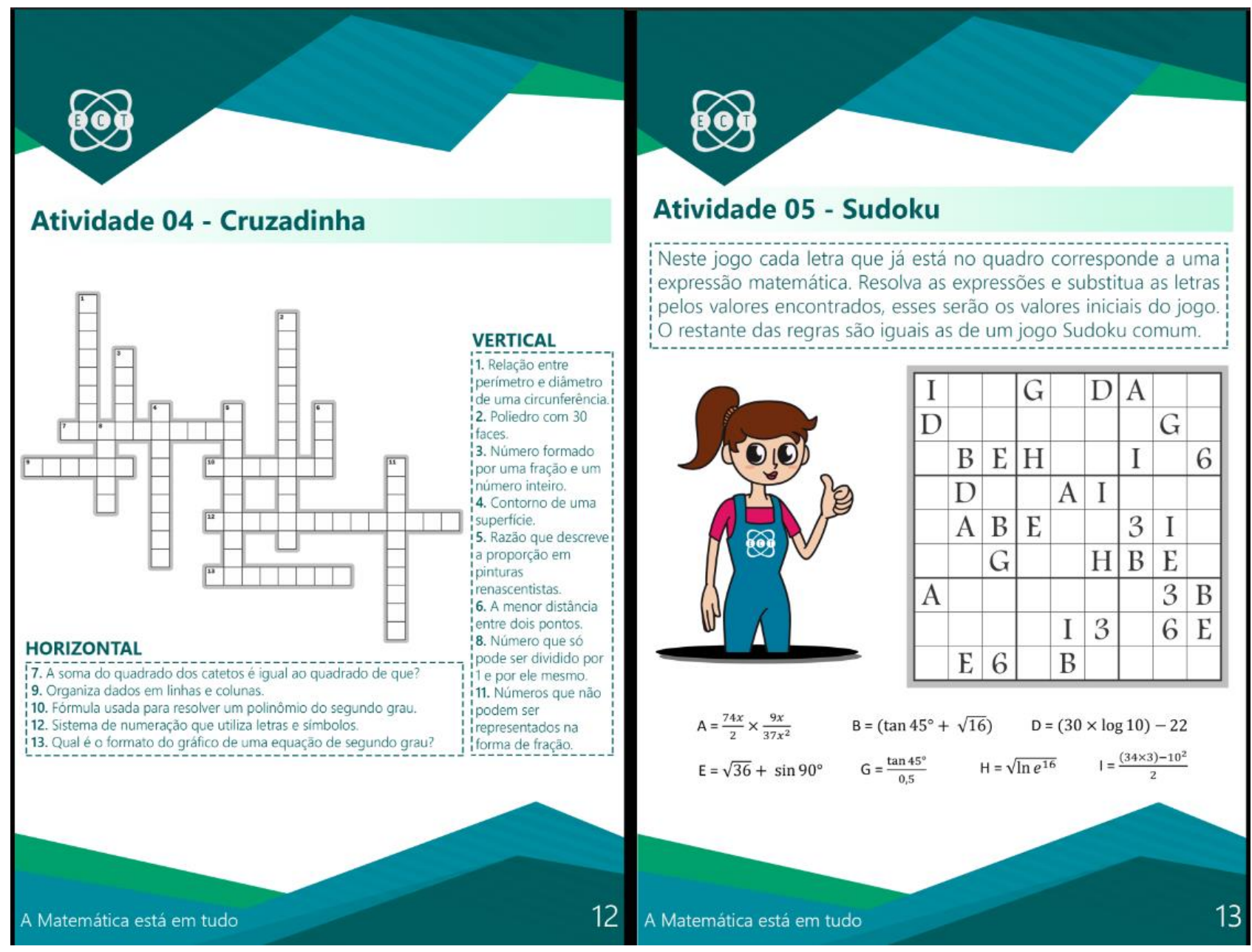

Fonte: Adaptado de A Matemática está em tudo (2020). 


\section{Respostas}

Como o intuito da revista elaborada é estimular o aprendizado de maneira geral com foco na matemática, o leitor precisa de informações para verificar se está conseguindo resolver as atividades. Seja para confirmar se as respostas estão corretas, ou para encontrar a solução de algum exercício que está com dificuldade, o leitor pode olhar a última página da revista que está representada na Figura 5.

Figura 5 - Página de respostas.

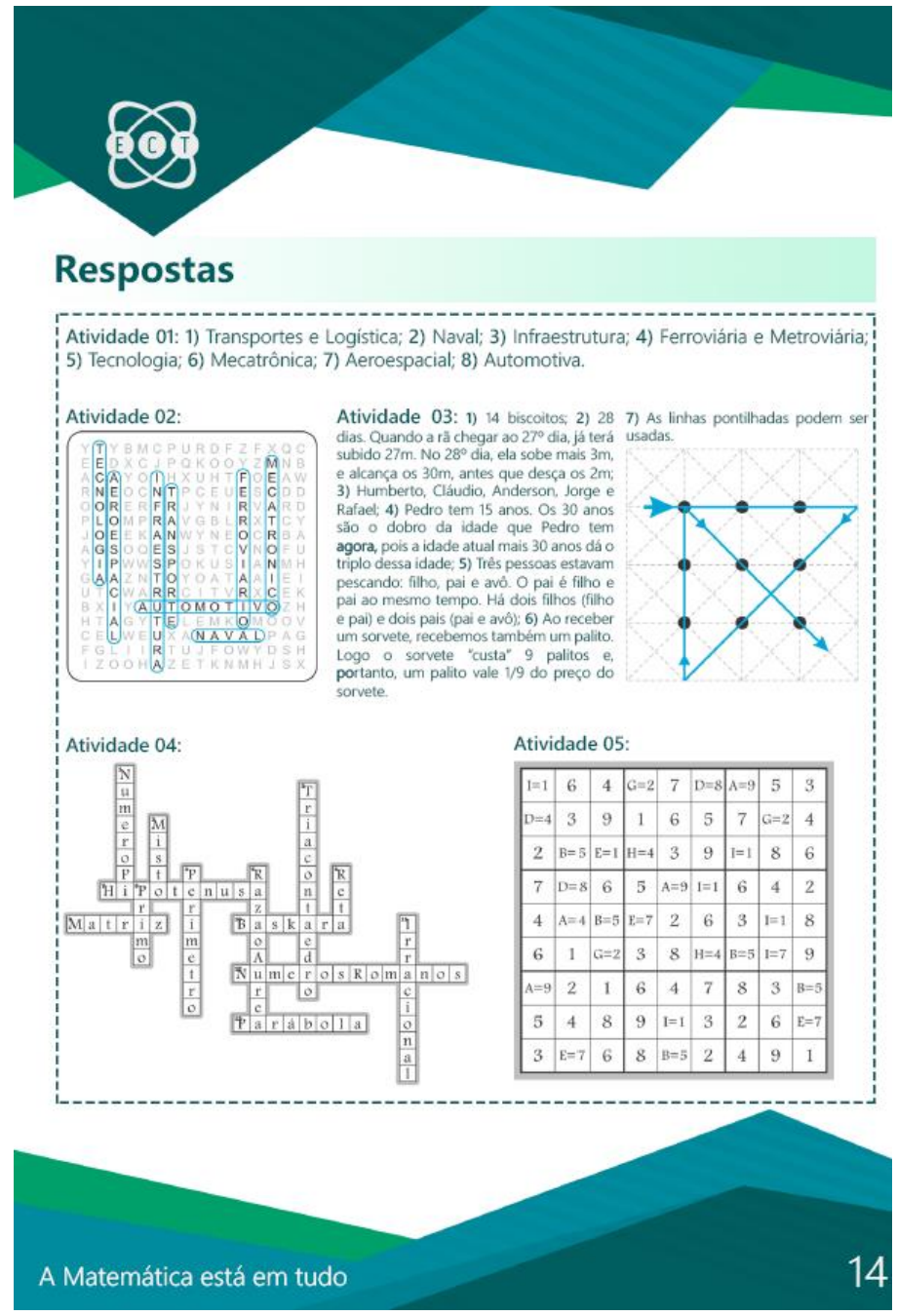

Fonte: Adaptado de A Matemática está em tudo (2020).

\section{Considerações FINAIS}

Com base nas informações obtidas sobre o aprendizado da matemática, observa-se a necessidade da adaptação do ensino a fim de melhorar o desempenho dos alunos. Como, dentre os objetivos do Espaço de Ciência e Tecnologia, contribuir para a popularização da ciência e da tecnologia é um dos principais, pensou-se na criação da revista A Matemática está em tudo.

A experiência prévia do lúdico facilitou a elaboração do conteúdo, pois o ECT desenvolve jogos, oficinas de robótica e possui diferentes materiais interativos desde sua 
criação. Outro fator relevante na elaboração desse projeto foram os resultados obtidos com as visitas que acontecem no espaço: a interação com os alunos visitantes evidenciou os seus níveis de conhecimento sobre os conteúdos utilizados. Ademais, como acadêmicos, os bolsistas do ECT, e seus colegas, têm contato direto com a matemática aplicada aos cursos do CTJ, o que colaborou para a decisão sobre os assuntos e formatos de abordagem adotados na revista.

Portanto, para atingir o objetivo de auxiliar o aprendizado de matemática, a revista será apresentada aos alunos de terceiro ano do ensino médio, tanto do sistema público quanto de colégios particulares, e aos calouros dos cursos do Centro Tecnológico de Joinville, campus da Universidade Federal de Santa Catarina. Os resultados serão documentados posteriormente, e os dados obtidos servirão para o desenvolvimento de outros projetos na área.

\section{REFERÊNCIAS}

CABRAL, Marcos Aurélio. A utilização de jogos no ensino de matemática. 2006. Monografia (Graduação) - Curso de Matemática Licenciatura. Universidade Federal de Santa Catarina, Florianópolis, 2006. Disponível em: https://repositorio.ufsc.br/xmlui/handle/123456789/96526. Acesso em: 14 abr. 2020.

KELLER, Susie Cristine ; GARCIA, Tatiana Renata ; SACCHELLI, Carlos Maurício ; MINIKOWSKI, Bruna . Jogo Das Matrizes: Aprendendo Conceitos de Tecnologia. In: 45ํㅜㅇ Congresso Brasileiro de Educação em Engenharia, 2017, Joinville. Anais do COBENGE 2017, 2017.

MENÁRGUEZ, Ana Torres. Conrad Wolfram: " $80 \%$ do que se aprende nas aulas de matemática não serve para nada". El País, 03 nov. 2017. Disponível em: https://brasil.elpais.com/brasil/2017/10/30/economia/1509378342_617037.html?ssm=TW_ CC. Acesso em: 16 abr. 2020.

NETO, F. F. et al. Dificuldade de aprendizagem no ensino fundamental e médio: a percepção de professores de sete escolas públicas de São Paulo - SP. Revista Psicopedagogia, São Paulo, v.32, n.97, p. 26-37, 2015. Disponível em $<$ http://pepsic.bvsalud.org/scielo.php?script=sci_arttext\&pid=S0103-

84862015000100004\&lng=pt\&nrm=iso>. Acesso em: 16 abr. 2020.

RAMOS EVANGELISTA, J. et al. Matemática lúdica ensino fundamental e médio. Educação em Foco / UNISEPE, n.6, p. 26-36, 2013. Disponível em: https://portal.unisepe.com.br/unifia/wpcontent/uploads/sites/10001/2018/06/3matematica_ludica.pdf. Acesso em: 14 abr. 2020.

SANTOS, Cristina dos. Avaliação de conteúdo na disciplina de matemática no ensino médio. 2005. Monografia (Graduação) - Curso de Matemática Licenciatura. Universidade Federal de Santa Catarina, Florianópolis, 2005. Disponível em: https://repositorio.ufsc.br/xmlui/handle/123456789/96360. Acesso em: 14 abr. 2020.

SOUZA, Flávio de. O papel da História da Matemática no ensino da Matemática: O que pensam os Pesquisadores atuais. 2008. Monografia (Graduação) - Curso de Matemática Licenciatura. Universidade Federal de Santa Catarina, Florianópolis, 2008. Disponível em: https://repositorio.ufsc.br/handle/123456789/96614. Acesso em: 16 abr. 2020. 
TORRES, R.; TREVISOL, N. Perfil do graduando UFSC: série apresenta resultados de pesquisa nacional realizada com estudantes. Disponível em: https://noticias.ufsc.br/2019/05/perfil-do-graduando-ufsc-serie-apresenta-resultados-depesquisa-nacional-realizada-com-estudantes/. Acesso em: 20 abr. 2020.

\title{
MATHEMATICS IS EVERYTHING: JOURNAL OF ACTIVITIES FOR HELP IN LEARNING OF HIGH SCHOOL MATHEMATICS
}

\begin{abstract}
This journal was developed in order to contribute to the teaching of mathematics to students in the third year of high school, and members of the initial stages of courses at the Technological Center of Joinville (CTJ) of the Federal University of Santa Catarina (UFSC). The purpose of this journal is to resume some content of the mathematics discipline in a playful and uncomplicated way, in order to develop the interest of readers and improve their understanding of the subjects covered.
\end{abstract}

Keywords: teaching, mathematics, high school 